University of Nebraska - Lincoln

DigitalCommons@University of Nebraska - Lincoln

2010

\title{
Patterns of drug use and abuse among aging adults with and without HIV: A latent class analysis of a US Veteran cohort
}

Traci C. Green

Yale School of Public Health

Trace Kershaw

Yale School of Public Health

Haiqun Lin

Yale School of Public Health

Robert Heimer

Yale Center for Interdisciplinary Research on AIDS

Joseph L. Goulet

Yale Center for Interdisciplinary Research on AIDS

See next page for additional authors

Follow this and additional works at: https://digitalcommons.unl.edu/publichealthresources

Part of the Public Health Commons

Green, Traci C.; Kershaw, Trace; Lin, Haiqun; Heimer, Robert; Goulet, Joseph L.; Kraemer, Kevin L.; Gordon, Adam J.; Maisto, Steve A.; Day, Nancy L.; Bryant, Kendall; Fiellin, David A.; and Justice, Amy C., "Patterns of drug use and abuse among aging adults with and without HIV: A latent class analysis of a US Veteran cohort" (2010). Public Health Resources. 174.

https://digitalcommons.unl.edu/publichealthresources/174

This Article is brought to you for free and open access by the Public Health Resources at DigitalCommons@University of Nebraska - Lincoln. It has been accepted for inclusion in Public Health Resources by an authorized administrator of DigitalCommons@University of Nebraska - Lincoln. 


\section{Authors}

Traci C. Green, Trace Kershaw, Haiqun Lin, Robert Heimer, Joseph L. Goulet, Kevin L. Kraemer, Adam J. Gordon, Steve A. Maisto, Nancy L. Day, Kendall Bryant, David A. Fiellin, and Amy C. Justice 


\title{
Patterns of drug use and abuse among aging adults with and without HIV:

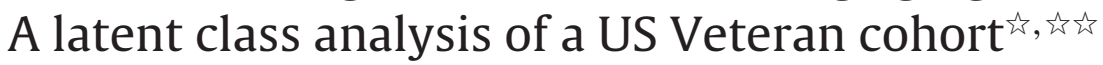

\author{
Traci C. Green ${ }^{\mathrm{a}, \mathrm{b}, *}$, Trace Kershaw ${ }^{\mathrm{a}, \mathrm{b}}$, Haiqun Lin ${ }^{\mathrm{c}}$, Robert Heimer ${ }^{\mathrm{b}, \mathrm{d}}$, Joseph L. Goulet ${ }^{\mathrm{b}, \mathrm{e}, \mathrm{f}}$, \\ Kevin L. Kraemer ${ }^{g}$, Adam J. Gordong,h, Steve A. Maisto ${ }^{i}$, Nancy L. Day ${ }^{\mathrm{j}}$, Kendall Bryant ${ }^{\mathrm{k}}$, \\ David A. Fiellin ${ }^{\mathrm{b}, \mathrm{f}, \mathrm{l}}$, Amy C. Justice ${ }^{\mathrm{b}, \mathrm{e}, \mathrm{f}}$
}

a Division of Chronic Disease Epidemiology, Yale School of Public Health, New Haven, CT, United States

b Yale Center for Interdisciplinary Research on AIDS, New Haven, CT, United States

${ }^{\mathrm{c}}$ Division of Biostatistics, Yale School of Public Health, New Haven, CT, United States

d Division of Epidemiology of Microbial Disease, Yale School of Public Health, New Haven, CT, United States

e Veterans Affairs Connecticut Healthcare System, West Haven, CT, United States

${ }^{\mathrm{f}}$ Department of Internal Medicine, Yale University School of Medicine, New Haven, CT, United States

${ }^{g}$ Center for Research on Health Care, Division of General Internal Medicine, University of Pittsburgh School of Medicine, Pittsburgh, PA, United States

${ }^{\mathrm{h}}$ Mental Illness Research, Education, and Clinical Center of Co-Morbidity (VISN-4) and the Center for Health Equity Research and Promotion,

VA Pittsburgh Healthcare System, Pittsburgh, PA, United States

i Department of Psychology, Center for Health and Behavior, Syracuse University, Syracuse, NY, United States

j Department of Psychiatry, University of Pittsburgh School of Medicine, Pittsburgh, PA, United States

${ }^{k}$ Alcohol and AIDS Research, National Institute on Alcohol and Alcohol Abuse, Bethesda, MD, United States

${ }^{1}$ Investigative Medicine Program, Yale University School of Medicine, New Haven, CT, United States

\section{A R T I C L E I N F O}

\section{Article history:}

Received 22 October 2009

Received in revised form 23 February 2010

Accepted 24 February 2010

Available online 15 April 2010

\section{Keywords:}

Aging

Veterans

HIV

Substance-related disorders

Latent class analysis

Illicit drugs

Cohort studies

\begin{abstract}
A B S T R A C T
This study characterized the extent and patterns of self-reported drug use among aging adults with and without HIV, assessed differences in patterns by HIV status, and examined pattern correlates. Data derived from 6351 HIV-infected and uninfected adults enrolled in an eight-site matched cohort, the Veterans Aging Cohort Study (VACS). Using clinical variables from electronic medical records and sociodemographics, drug use consequences, and frequency of drug use from baseline surveys, we performed latent class analyses (LCA) stratified by HIV status and adjusted for clinical and socio-demographic covariates. Participants were, on average, age 50 (range 22-86), primarily male (95\%) and African-American (64\%). Five distinct patterns emerged: non-users, past primarily marijuana users, past multidrug users, current high consequence multidrug users, and current low consequence primarily marijuana users. HIV status strongly influenced class membership. Non-users were most prevalent among HIV uninfected (36.4\%) and current high consequence multidrug users (25.5\%) were most prevalent among HIV-infected. While problems of obesity marked those not currently using drugs, current users experienced higher prevalences of medical or mental health disorders. Multimorbidity was highest among past and current multidrug users. HIV-infected participants were more likely than HIV-uninfected participants to be current low consequence primarily marijuana users. In this sample, active drug use and abuse were common. HIV-infected and uninfected Veterans differed on extent and patterns of drug use and on important characteristics within identified classes. Findings have the potential to inform screening and intervention efforts in aging drug users with and without HIV.
\end{abstract}

(c) 2010 Elsevier Ireland Ltd. All rights reserved.

\footnotetext{
A summary table of the results is available with the online version of this article. Please see Appendix A at doi:10.1016/j.drugalcdep.2010.02.020.

放访 Disclaimer: The views expressed in this article are those of the authors and do not necessarily reflect the position or policy of the Department of Veterans Affairs.

* Corresponding author at: 111 Plain St. Building, Rm 111, Providence, RI 02903.

USA. Tel.: +1 401444 3845; fax: +1 4014445040.

E-mail address: traci.c.green@brown.edu (T.C. Green).
}

\section{Introduction}

Drug use among older adults in the US is occurring at unprecedented high levels and growing. The baby boom generation (i.e., people born 1946-1964) has higher prevalences of lifetime drug use compared to all previous generations and appears to be continuing their drug use later into life (Han et al., 2009a). In 2007, all adults aged 50-59 were baby boomers; recent national data reveal that in the same year the prevalence of self-reported past year illicit drug use in this age group nearly doubled from 2002 figures (Han 
et al., 2009b). Updated projections forecast that by 2020, the number of adults 50 or older with substance use disorder will more than double from 2.8 million in 2002-2006 to 5.7 million (Han et al., 2009b), a projection $30 \%$ higher than previously estimated (Colliver et al., 2006; Gfroerer et al., 2003). The enormity of this problem is compounded by under-recognition of substance use in older people (Levin and Kruger, 2002), limited data on the types and patterns of their drug use (Levy, 1998; Lieberman, 2000), the lack of substance abuse treatment services for older adults (Office of Applied Studies, 2007), under-utilization of screening tools for primary care practitioners to identify substance abuse problems (Friedmann et al., 2001; Kim et al., 2007; Lewis, 1997), and the medical and psychological comorbidities that often accompany and complicate the health status of older drug users (Geriatric Mental Health Foundation, 2010; Reid and Anderson, 1997; Reid et al., 2002; Simoni-Wastila and Yang, 2006).

At the same time, HIV is increasingly affecting older populations because HIV-infected persons are living longer on more effective treatments while HIV incidence in this age group is on the rise. Approximately $10 \%$ of new HIV infections in the US occur among people over 50 years of age (Centers for Disease Control and Prevention, 2008). Drug use, especially by injection, is one of the primary modes of HIV and hepatitis transmission, and thus one might expect HIV-infected older adults to have higher prevalences of injection drug use (IDU) compared to their uninfected peers. On the other hand, HIV incidence among IDUs has declined by $50 \%$ or greater over the past 20 years (Des Jarlais et al., 2000; Lee et al., 2003), and, in many places, HIV transmission among IDUs has been associated with sexual transmission rather than unsafe injection (Centers for Disease Control and Prevention, 2009; Kral et al., 2001; Strathdee et al., 2001). Furthermore, most illicit drug use in the US is non-injection (Substance Abuse and Mental Health Services Administration, 2009). Regardless of HIV status and transmission category, patterns of current drug use are poorly understood in older adults (Rabkin et al., 2004; Rosenberg, 1995; Schlaerth, 2007).

The nexus of these three issues - drug use, HIV, and aging - is an understudied yet looming problem. Evidence suggests that HIV may speed aging and exacerbate problems of older age. Active drug use contributes to poor health outcomes for people with and without HIV alike (AETC, 2006; Bruce et al., 2008; Kapadia et al., 2005), and may be particularly harmful if addictive disorders persist later in life. Older adults with HIV may thus be disproportionately burdened by the negative consequences of ongoing drug abuse (Zanjani et al., 2007). For example, both older age and HIV infection are risk factors for unintentional fatal drug overdose (Darke and Zador, 1996; Tardiff et al., 1997; Wang et al., 2005). Biological mechanisms of this elevated risk may be due to changes in metabolism and body water content in older adults that can lead to higher serum drug concentrations over prolonged periods, thereby increasing risks of unintentional injuries such as drug overdose.

Few studies have been conducted with sufficient power to contrast drug use by HIV status and age; even fewer provide generalizable data (Levy, 1998; Lieberman, 2000) or detailed information regarding medical and psychiatric comorbidities related to substance use problems. One study, limited by sample size, found that lifetime drug dependence was higher for the HIV-infected than uninfected individuals, and that expected age-associated declines in diagnoses of dependence were not detected among the HIVinfected (Rabkin et al., 2004). Analysis of data from a larger, more diverse sample is needed to assist clinicians and policy makers in developing evidence-based responses to changing patterns of drug use in aging populations.

In this paper, we used data from the Veterans Aging Cohort Study (VACS) (Justice et al., 2006a), a longitudinal, prospectively consented, observational cohort study conducted among HIV-infected Veterans and age-, race- and site-matched HIV uninfected controls receiving medical care at one of eight US Veterans Administration (VA) facilities to: (1) characterize patterns of self-reported drug use in a large and diverse cohort of aging HIV-infected and uninfected US Veterans and analyze their construct validity; (2) assess pattern differences by HIV status; and (3) describe demographic, medical and psychiatric pattern correlates within this population. To accomplish these aims, we employed latent class analysis (LCA) (Agrawal et al., 2007; Lubke and Muthen, 2005; Muthen, 2006) to identify patterns of behavior, using all available baseline VACS information. We chose this empirical approach to minimize the potential for measurement error, bias, or oversimplification (Kapadia et al., 2005) inherent when a priori definitions are used to aggregate and categorize complex behaviors.

\section{Methods}

\subsection{Sample}

VACS has been described extensively elsewhere (Conigliaro et al., 2004; Justice, 2006; Justice et al., 2006a,b, 2001); design and population characteristics pertinent to this analysis are reported here. Initiated in 2002, the eight-site VACS aimed to explore comorbidities and behaviors affecting medical outcomes in the broader context of aging and HIV (Justice et al., 2006a, 2001). HIV-infected participants were recruited from VA infectious disease clinics; uninfected participants were recruited from VA general medicine clinics. Participants are largely male, representative of the VA population in care for HIV (Justice et al., 2006a). VACS is characterized by a network of administrative, clinical, and research resources that allows linkage of annual self-reported survey data to electronic medical records (EMR), vital statistics, pharmacy prescriptions, and healthcare use. Annual loss to follow up is $<5 \%$.

\subsection{Measures}

2.2.1. Drug use and consequences. The VACS baseline survey included items on frequency of use (Centers for Disease Control and Prevention, 2002) of marijuana, heroin/opioids, cocaine/crack, and stimulants (amphetamines, speed, crystal methamphetamine). Responses for marijuana and stimulant/cocaine use were: never, no use in the past year, some use in the past year (monthly or less often), and heavy use in the past year (weekly to daily use). For heroin/opioids the response options were never, not in the past year, any past year use. Due to sparseness of data and lack of clinically meaningful differences in their use, stimulant use was grouped with cocaine/crack use. The degree of consequence (high, low) experienced due to drug use was derived from an item within the Michigan Composite International Diagnostic Interview (CIDISF) (Kessler et al., 1998): "In the past 12 months, did your use of drugs ever interfere with your work at school, or a job, or at home?" Responses were never drug use, use more than 1 year ago (problems may or may not have been experienced), no problems experienced in the past year, or problems experienced in the past year. Together, these items comprised the indicators for the LCA.

2.2.2. Covariates. Variables known to be associated with drug use that might differentiate the patterns included socio-demographics, comorbidities (hepatitis C (HCV), medical and psychiatric conditions) (Kilbourne et al., 2001), history of and past year injection drug use, and past year receipt of VA substance abuse and mental health treatment. The selection of candidate covariates of the LCA was a theoretically driven one that was tested statistically in the LCA. The theoretical model informing our analyses was Gelberg's Behavioral Model for Vulnerable Populations, which amends Andersen's Behavioral Model to explicitly include domains especially relevant to vulnerable populations (e.g., the homeless) to explain and 
predict personal health practices (Gelberg et al., 2000). In this model, health outcomes and behaviors are functions of predisposing factors, enabling resources, and need. Predisposing domains traditionally include demographics like age, gender, and ethnicity, but were expanded to include vulnerable domains such as lifestyle instability. In this analysis, we considered HIV positive Veterans as a vulnerable population. Substance abuse, race/ethnicity, and gender are conceptualized as predisposing factors; enabling resources include having a regular care provider, HAART, and income; need encompasses health status, presence of depressive symptoms, and comorbidities; health behaviors act as intermediate outcomes and include adherence to medication; and outcomes are disease progression and death. The focus of the present analysis is on the interplay of predisposing, enabling, and need factors as covariates of the LCA; the remaining domains are the subject of future analyses. Socio-demographics included age, race/ethnicity, education level, income, marital status, smoking, body mass index ((BMI) calculated based on self-reported height and weight) and having ever been homeless or marginally housed. Current problem drinking was assessed by the AUDIT-C (Bush et al., 1998). Other covariates included lifestyle instability (Gordon et al., 2006; Kim et al., 2006; McFarland et al., 2003; Shapiro et al., 1999; Song et al., 2000), approximated by past month homelessness and concern about food availability, and quality of life (mental, physical composite scores) which was captured by the Short Form-12 (SF-12) (Ware et al., 1996). Comorbidities were identified using International Classification of Diseases, 9th revision (ICD-9-CM) codes from the participant's EMR, grouped into clusters of medical and psychiatric disease diagnoses, as previously reported (Goulet et al., 2005, 2007). For participants with HIV, concurrent AIDSassociated illness occurring 1 year before and 6 months after baseline was defined according to the Centers for Disease Control and Prevention's (1993) case definition.

\subsection{Analysis}

2.3.1. Overview. We used LCA, a statistical method for creating meaningful subgroups, or latent classes, based on similarities in responses to a set of observed indicators. It is assumed that the observed variables are independent from one another once conditioned on the latent variable, an assumption known as local independence (Hagenaars and McCutcheon, 2002). LCA produces: (a) the prevalence of each latent class (i.e., prior probability that a randomly chosen person will be in each class) and (b) the probability of response to an indicator, conditional on the latent class. Class categorizations are based on the prevalence of the latent classes and are mutually exclusive and exhaustive. While an individual has a probability of membership in all of the latent classes, theoretically, they belong to one true class. Based on the profile of the response indicators, a putative name for the class can be derived. LCA has a number of advantages. It can incorporate covariates that may influence class membership (Muthen, 2004). LCA has been used previously in evaluations of subjects with substance use disorders (e.g., Monga et al., 2007). Also, LCA employs a full information maximum likelihood approach that allows for analysis of all available data, assuming data are missing at random. Therefore we were able to model using all available baseline cases instead of deleting those with missing drug use data.

2.3.2. Modeling approach. First, we constructed a LCA model using the entire sample (regardless of HIV status). We systematically built from simple unadjusted to more complex adjusted models. Unadjusted models considered one to seven classes. To identify the optimal number of latent classes and the best fitting model, we sought to minimize the Bayesian Information Criteria (BIC), maximize entropy, a summary measure that conveys classification quality (Muthen and Muthen, 2007), and yield interpretable latent classes of $>1 \%$ prevalence. Once a final model was selected, we tested for differences by HIV status and then incorporated covariates in an adjusted LCA model. Results describe the empirically derived classes and their construct validity. Mplus version 5.1 software (Muthen and Muthen, 2007) was used to fit LCA models.

2.3.3. Construct validity. Adjusted latent classes were compared to other classifications of drug abuse and dependence obtainable through medical records and VACS surveys. These included, respectively, ICD-9-CM diagnoses and CIDI-SF score $\geq 4$, indicating high probability of fulfilling DSM-IV drug dependence criteria (Kessler et al., 1998; Robins et al., 1988). A search of the participant's EMR 1 year prior and 6 months after the survey visit date was conducted of VA administrative records at the Austin Automation Center (Austin, TX) for ICD-9-CM diagnosis codes 291.00-292.99 and 303.00-305.99 (Druss and Rosenheck, 2000). Patients were coded dichotomously according to whether or not their EMR noted abuse and/or dependence of alcohol or drugs. Using $\chi^{2}$ and Kappa statistics, we assessed how these related indicators mapped onto the derived latent classes (Orlando et al., 2004, 2005; Tucker et al., 2006) as "validating indicators".

2.3.4. Differences by HIV status. By including HIV status as a covariate that could have class-varying probabilities and comparing the fit of nested models (Muthen and Muthen, 2007) using $\chi^{2}$ tests we assessed for differences by HIV status. Direct effects (i.e., HIV effects drug use indicators directly versus through the latent class) were tested in similar fashion. Based on these results, subsequent LCA analyses were stratified by HIV status, to characterize diseasespecific class differences and correlates.

2.3.5. Adjusting for covariates. To examine correlates of class membership, we conducted latent class regression. We adjusted for covariates by employing a stepped modeling approach (Delucchi et al., 2004). First, taking the modal predicted most likely class from the unadjusted LCA as the outcome, class-specific differences were tested for all covariates using bivariate analyses (Wald $\chi^{2}$ tests for categorical variables, ANOVAs or Kruskall-Wallace test for continuous variables), stratified by HIV status. Due to the large number of comparisons made, the overall $\alpha$ level was Bonferroni-corrected to $p<.0013(\alpha=.05 / 39)$. Variables found to be significant were then entered into a multinomial logistic regression of the modal predicted most likely class to determine factors independently associated with membership (Ghandour et al., 2008). The resulting significant covariates were considered candidates for the adjusted latent class regression model. Then, HIV-specific LCAs were reestimated incorporating the candidate variables and checking that covariates excluded earlier in the analysis did not significantly improve fit, reduce variance, or measurably ( $\geq 10 \%$ ) alter parameter estimates. Last, by testing nested models, any candidate variables that did not help differentiate classes were dropped from the final adjusted latent class regression models. Results present the classand HIV-specific socio-demographic and health status variables. This study was approved by institutional review boards at the Yale School of Medicine and the VA Connecticut Healthcare System, West Haven.

\section{Results}

\subsection{Study sample}

Participants were, on average, age 50 (range 22-86), primarily male and African-American (Table 1 ). HIV-infected participants were significantly more likely to be African-American, HCV seropositive, not married or living with a partner, and to have 
Table 1

Characteristics of the HIV-infected $(n=3160)$ and HIV uninfected $(n=3191)$ VACS participants.

\begin{tabular}{|c|c|c|c|c|c|}
\hline & \multicolumn{2}{|l|}{ HIV- } & \multicolumn{2}{|l|}{ HIV+ } & \multirow[t]{2}{*}{$p$-value } \\
\hline & $N$ & $\%$ & $N$ & $\%$ & \\
\hline Age, mean (SD) & 3191 & $50.7(10.0)$ & 3160 & $49.4(8.8)$ & $<.0001$ \\
\hline Vietnam era cohort $^{\dagger}$ & 2016 & 63.2 & 1881 & 59.5 & .003 \\
\hline Male & 2938 & 92.1 & 3080 & 97.5 & $<.0001$ \\
\hline Race White & 782 & 24.5 & 637 & 20.2 & 0.002 \\
\hline African-American & 1974 & 61.9 & 2103 & 66.5 & \\
\hline Hispanic & 320 & 10.0 & 297 & 9.4 & \\
\hline Other & 115 & 3.6 & 123 & 3.9 & \\
\hline Education $\leq$ high school & 1294 & 41.0 & 1276 & 40.7 & .79 \\
\hline Ever homeless & 1337 & 41.9 & 1515 & 47.9 & $<.0001$ \\
\hline Homelessness, past month & 380 & 11.9 & 256 & 8.1 & $<.0001$ \\
\hline Married/living with partner & 1240 & 39.1 & 711 & 22.8 & $<.0001$ \\
\hline Annual income $\geq \$ 25,000$ & 1046 & 32.8 & 747 & 23.6 & $<.0001$ \\
\hline BMI categories Obese & 1242 & 39.2 & 407 & 13.0 & $<.0001$ \\
\hline Overweight & 1186 & 37.4 & 1146 & 36.6 & 0.49 \\
\hline Normal & 702 & 22.1 & 1457 & 46.5 & $<.0001$ \\
\hline Underweight & 39 & 1.2 & 123 & 3.9 & $<.0001$ \\
\hline Smokes currently & 1394 & 44.1 & 1656 & 52.6 & $<.0001$ \\
\hline Mean (SD) SF-12 composite score Mental & 3169 & $47.5(11.8)$ & 3149 & $46.7(11.2)$ & 0.004 \\
\hline Physical & 3181 & $42.2(11.4)$ & 3148 & $43.5(10.6)$ & $<.0001$ \\
\hline $\mathrm{HCV}+$ & 767 & 24.0 & 1474 & 46.6 & $<.0001$ \\
\hline Medical disease cluster & 2236 & 70.1 & 1879 & 59.5 & $<.0001$ \\
\hline Diabetes & 730 & 22.9 & 402 & 12.7 & $<.0001$ \\
\hline Hypertension & 1705 & 53.4 & 944 & 29.9 & $<.0001$ \\
\hline Renal disease & 90 & 2.8 & 120 & 3.8 & .003 \\
\hline Pulmonary disease & 365 & 11.4 & 285 & 9.0 & .001 \\
\hline Liver disease (not including hepatitis) & 29 & 0.9 & 59 & 1.9 & .001 \\
\hline Vascular disease & 473 & 14.8 & 252 & 8.0 & $<.0001$ \\
\hline Psychiatric disease cluster & 880 & 27.6 & 738 & 23.3 & $<.0001$ \\
\hline Schizophrenia & 210 & 6.6 & 134 & 4.2 & $<.0001$ \\
\hline Major depression, bipolar & 569 & 17.8 & 539 & 17.1 & .41 \\
\hline Post traumatic stress disorder & 407 & 12.7 & 247 & 7.8 & $<.0001$ \\
\hline Medical \& psychiatric disease cluster ${ }^{\ddagger}$ & 655 & 20.5 & 530 & 16.8 & $<.0001$ \\
\hline Past year treatment Substance abuse & 536 & 16.8 & 449 & 14.2 & 0.004 \\
\hline Methadone maintenance & 159 & 5.0 & 144 & 4.6 & 0.41 \\
\hline Mental health & 1166 & 36.5 & 926 & 29.3 & $<.0001$ \\
\hline IVD past year & 137 & 4.3 & 231 & 7.4 & $<.0001$ \\
\hline Alcohol use past year & 2031 & 67.4 & 2048 & 68.4 & 0.39 \\
\hline AUDIT-C score (mean, SD) & 3084 & $2.7(2.9)$ & 3026 & $2.6(2.6)$ & 0.014 \\
\hline Problem drinking cutoff ${ }^{+}$ & 995 & 31.2 & 911 & 28.8 & 0.041 \\
\hline ICD-9 baseline diagnosis*: Alcohol abuse/dependence & 740 & 23.2 & 586 & 18.5 & $<.0001$ \\
\hline Drug abuse/dependence & 799 & 25.0 & 793 & 25.1 & 0.96 \\
\hline CIDI-SF defined drug dependent ${ }^{*}$ & 409 & 13.5 & 449 & 14.9 & 0.14 \\
\hline AIDS-associated illnesses, past year & - & - & 707 & 22.4 & NA \\
\hline
\end{tabular}

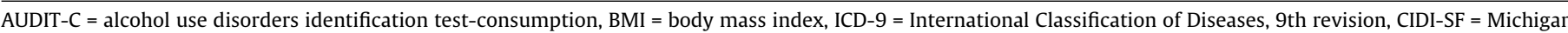
composite international diagnostic interview, short form, $\mathrm{SD}=$ standard deviation, IVD = intravenous drug use, $\mathrm{HCV}=$ hepatitis $\mathrm{C}$ virus, $\mathrm{NA}=$ not applicable.

* Variables used in validation of derived latent classes.

Defined as born on or before December 31, 1955 (i.e., aged 18 or older at the last draft in 1973).

$\ddagger$ Has at least one ICD-9-CM diagnosis within each of the medical and psychiatric disease clusters (i.e., multimorbidity).

+ Defined as $>4$ on AUDIT-C score.

past and recent histories of homelessness. Alcohol use was similarly high across HIV status. Drug use was reported by HIV-infected and uninfected participants, with a significantly higher prevalence ( $p<.0001$ for all indicators) among the former. Self-reported drug use was higher than that captured by ICD9 diagnoses (Fig. 1) and other drug abuse/dependence criteria (Table 1).

\subsection{Latent classes based on drug use indicators: overall}

For the full sample ( $N=6351)$, a five class unadjusted model provided the best fit to the observed data (entropy 5 class $=0.94$, BIC 5 class $=39472.3$ versus BIC 4 class $=40126.5$ ) and defined clinically interpretable and relevant subgroups labeled for convenience based on their profiles of response to the latent class indica- tors as non-users, past primarily marijuana users, past multidrug users, current high consequence multidrug users, and current low consequence primarily marijuana users. Local independence was checked by looking at bivariate residuals conditional on class membership associated with each pair of drug use indicators. $p$-Values associated with these tests remained below critical values for the stratified HIV positive model and two violations were found with critical values flagging a significant dependence in the HIV negative model. To account for these few large residuals, direct effects were tested between the indicators (cocaine/stimulate use, heroin/opiate use and drug use consequences). Inclusion of the direct effects did not further improve model fit or significantly change the estimated model parameters or probabilities so they were not retained in the final models. HIV status strongly influenced class membership, evidenced by significantly improved model fit 


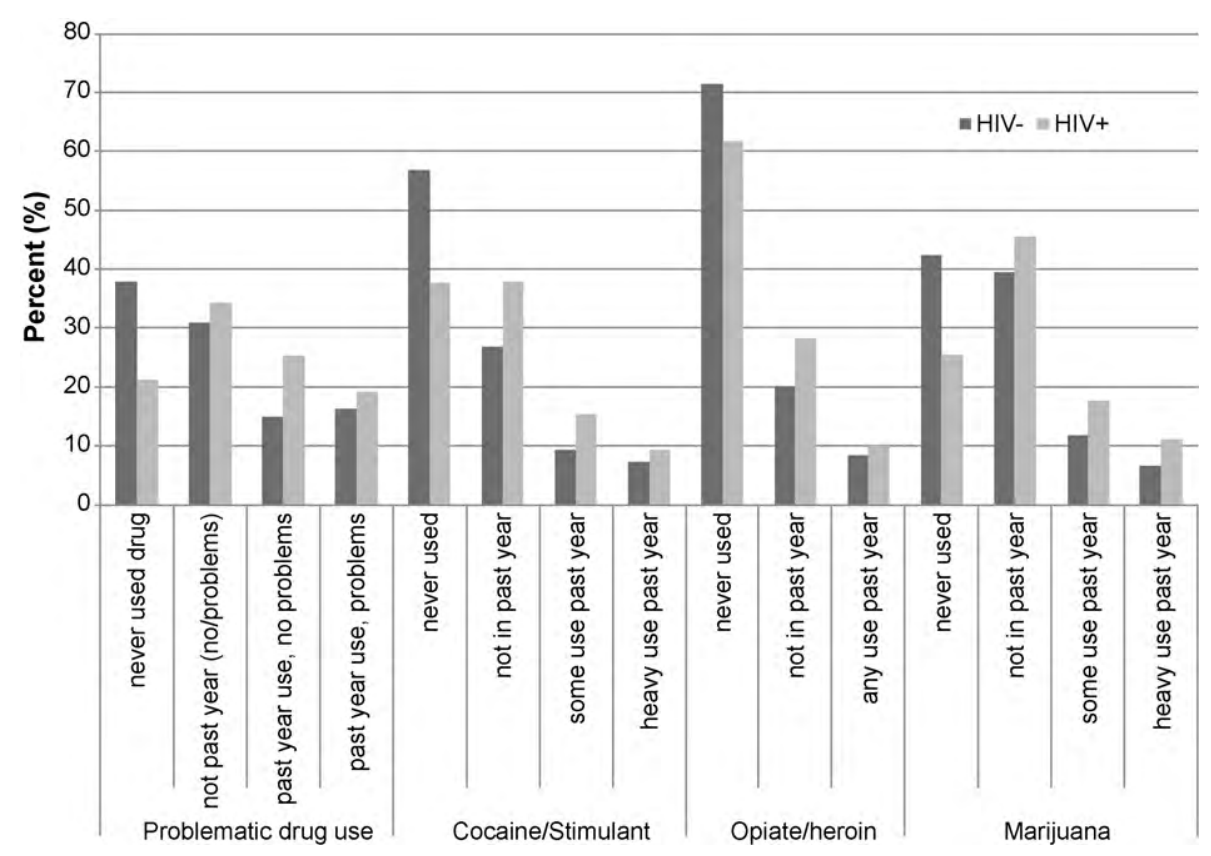

Fig. 1. Latent class indicators of drug use among HIV-infected and uninfected VACS participants $(n=6351)^{*}$.

Those who indicated 'not past year use' for problematic drug use may or may not have experienced problems in the past with their drug use.

$\left(\chi^{2}\right.$ difference $=279.56$, degrees of freedom $\left.=4, p<.0001\right)$. HIV status significantly $(p<.001)$ differentiated 18 of the 20 possible class membership combinations (five comparisons, k-1 classes). Compared to non-users (reference group), HIV-infected subjects were more likely to be classified as past multidrug users (OR 2.3), current multidrug users (OR 2.4 ) or, most likely, as current primarily marijuana users (OR 3.3, all $p<.0001$ ).

\subsection{HIV-specific LCAs}

Based on these strong HIV effects, we conducted unadjusted LCAs stratified by HIV status, and found that the 5 class model again fit best (HIV-infected: BIC 5 class $=21215.3$ versus BIC 4 class $=21463.2$; HIV uninfected: BIC 5 class $=21215.3$ versus BIC 4 class $=21463.2$ ). When the resultant classes were treated as outcomes in bivariate and multivariable analyses, 19 candidate covariates were identified for consideration in adjusted LCA models. In fitting the multinomial regressions, we detected nonlinearity in effects for age, anticipated from known relationships between aging and drug use and possible generational effects (Rosenberg, 1995; Schlaerth, 2007). At age 60, probability of membership in a current drug use class was 0.19 for the HIV-infected and 0.087 for the HIV-infected; at age 70 these probabilities were 0.066 and 0.032 , respectively.

In the final latent class regression modeling step, adjusting the LCA models retained the underlying structures of the unadjusted models, improved model fit, and maintained high entropy (HIV-infected: entropy $=.92$, BIC 5 class $=17035.4$; HIV uninfected: entropy $=0.93$, BIC 5 class $=15258.5$ ). While the item-response probability profiles were similar by HIV status for the non-users and past multidrug user classes, they differed by HIV status for past primarily marijuana and all current user classes (Table 2). Compared to the HIV uninfected, the probability of reporting high consequence drug use was lower for the HIV-infected current multidrug users (0.64 HIV+ versus 0.74 HIV-). For the low consequence primarily marijuana use class, HIV-infected participants were more likely to have a history of cocaine/stimulant use ( 0.43 HIV+ versus 0.32 HIV-) whereas the HIV uninfected were more likely non-users of cocaine/stimulants ( $0.47 \mathrm{HIV}-$ versus $0.35 \mathrm{HIV}+$ ).

\subsection{Construct validity}

3.4.1. Agreement of LCA classes and clinical diagnoses. For both HIVinfected and uninfected, Kappa statistics were moderately high between the high consequence multidrug users and drug dependence according to CIDI ( $K=0.55 \mathrm{HIV}+, K=0.68 \mathrm{HIV}-)$ and ICD-9 $(K=0.45 \mathrm{HIV}+, K=0.59$ HIV-). Lower bounds of the Kappa statistics for all measures of agreement lay above the suggested 0.40 minimum (Landis and Koch, 1977; Sim and Wright, 2005). The remaining classes had small and negative Kappas with the two drug dependence criteria. Regardless of HIV status, the non-user class had the most negative Kappas (range: -0.32 to -0.18 ) with the drug dependence criteria. Negative Kappas mean agreement occurred less often than predicted by chance, suggesting genuine disagreement (Juurlink and Detsky, 2005), which is expected in the non-use and low drug use categories. Most members of the current multidrug users class exhibited abuse/dependence criteria, regardless of HIV status, though this was consistently lower among the HIV-infected. In sum, results suggest construct validity of the latent classes was achieved.

\subsection{Class descriptions}

Table 3 displays socio-demographic and health status characteristics of the adjusted drug classes by HIV status. Hispanic/other ethnicity, sex (HIV-infected) and education level (HIV uninfected) were not different across classes. Health status variables not statistically significant across class were BMI categories for overweight and underweight, renal disease, pulmonary disease, and, for the HIV uninfected, the medical disease cluster. For HIV-infected participants, vascular disease prevalence did not differ by class. All other variables reported were statistically significant across classes by Wald tests using a Bonferroni-adjusted $p$-value of 0.0013 . Class descriptions below summarize findings reported in Tables 2-4 but focus on drug use and health status results only, in the interest of space.

3.5.1. Class 1: non-users (VACS prevalence: $36.4 \%$ HIV-, $19.6 \%$ HIV+). Measures of mental quality of life were generally high for non- 


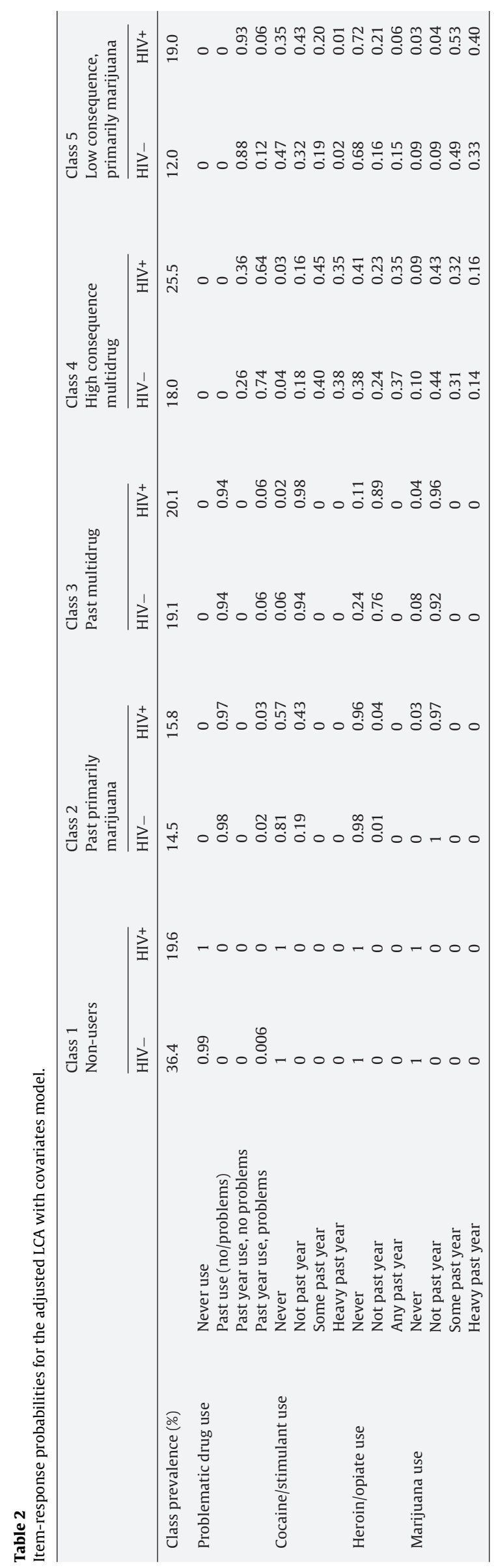

users, while for the HIV uninfected, the median physical composite score suggested a lower quality of life. Obesity in this class was the second highest at $15.7 \%$ of the HIV-infected and $42.0 \%$ of the HIV uninfected. Past year alcohol use was common but AUDIT-C scores were low and, as expected, non-users had a low prevalence of substance abuse or mental health treatment. Non-users had high prevalences of chronic medical disease (i.e., diabetes, hypertension and vascular disease) and the lowest prevalence of psychiatric diseases of all classes. HCV was relatively low for HIV-infected and uninfected non-users. Compared to all other classes, HIV-infected subjects in this class experienced the fewest AIDS-associated illnesses.

3.5.2. Class 2: past primarily marijuana users (VACS prevalence: $14.5 \%$ $H I V-, 15.8 \% H I V+)$. The prevalence of this class was similar by HIV status. Past primarily marijuana users shared similar characteristics with the non-user class, regardless of HIV status. Differences were primarily socio-demographic (more non-minorities, higher educational status among HIV+; highest income and employment). Additionally, past primarily marijuana users more often reported more past year alcohol use although their AUDIT-C scores were similar to those of non-users. Medical but not psychiatric diseases were less prevalent than in non-users. The HIV-infected had a higher prevalence of AIDS-associated illnesses than in non-users but this prevalence was low relative to other classes with drug use histories.

3.5.3. Class 3: past multidrug users (VACS prevalence: $19.1 \%$ HIV-, 20.1\% HIV+). Overall prevalence of this class was similar by HIV status, but the populations reported different health and drug use experiences. A history of injection drug use was common among the past multidrug users, more so among the HIV-infected. Past multidrug users had the lowest reported alcohol use of all classes but there were higher AUDIT-C scores among those continuing to drink. This class also reported more recent treatment for substance abuse and mental health problems than classes 1,2 and 5. Past multidrug users suffered from significant health problems, reflected in low SF-12 physical and mental scores. The highest prevalences of obesity and medical diseases were found in this class. Among the HIV-infected, chronic medical diseases (i.e., diabetes, hypertension, vascular disease) and HCV peaked in this class.

3.5.4. Class 4: high consequence, multidrug users (VACS prevalence: $18.0 \% \mathrm{HIV}-, 25.5 \% \mathrm{HIV}+$ ). History of and current drug injection distinguished this class, with current injection more common among the HIV-infected. Evidence suggested that some members of this class transitioned from injecting to non-injecting drug use $(42.3 \%$ ever to $19.8 \%$ past year HIV-, $57.9 \%$ ever to $27.1 \%$ past year HIV+), though available data cannot discern when such changes took place. Continued drug use was primarily through smoking marijuana and non-injection use of heroin/opioids and cocaine (including crack). Class members also reported current problem drinking. History of recent substance abuse treatment and methadone treatment was greater in this than for all other classes and they reported poor quality of life scores. Prevalence of obesity was low as were medical diseases associated with obesity, especially diabetes, hypertension, and vascular disease (HIV- only). On the other hand, prevalence of HCV and psychiatric diagnoses-in particular, major depression and bipolar-was high. Co-occurrence of medical and psychiatric disease (i.e., multimorbidity) and AIDSassociated illness was highest in this class.

3.5.5. Class 5: low consequence, primarily marijuana (VACS prevalence: $12.0 \%$ HIV-, $19.0 \%$ HIV+). The distinct differences by disease status in this class were notable. Among the HIV-infected in this class, socio-demographics (e.g., non-minority, educational status, income, and stability) and low AUDIT-C scores were similar to 
Table 3

Characteristics of each of the five covariate-adjusted latent classes by HIV status.

\begin{tabular}{|c|c|c|c|c|c|c|c|c|c|c|}
\hline & \multicolumn{2}{|l|}{ Non-users } & \multicolumn{2}{|c|}{ Past primarily marijuana } & \multicolumn{2}{|c|}{ Past multidrug } & \multicolumn{2}{|c|}{ High consequence, multidrug } & \multicolumn{2}{|c|}{$\begin{array}{l}\text { Low consequence, } \\
\text { primarily marijuana }\end{array}$} \\
\hline & \multicolumn{2}{|l|}{ Class 1} & \multicolumn{2}{|l|}{ Class 2} & \multicolumn{2}{|l|}{ Class 3} & \multicolumn{2}{|l|}{ Class 4} & \multicolumn{2}{|l|}{ Class 5} \\
\hline & HIV- & HIV+ & HIV- & HIV+ & HIV- & HIV+ & HIV- & HIV+ & HIV- & HIV+ \\
\hline Class prevalence (\%) & 36.4 & 19.6 & 14.5 & 15.8 & 19.1 & 20.1 & 18.0 & 25.5 & 12.0 & 19.0 \\
\hline Age $\leq 40$ & 15.0 & 20.6 & 20.6 & 17.6 & 4.6 & 3.3 & 8.0 & 7.3 & 14.6 & 18.5 \\
\hline $41-50$ & 25.8 & 30.4 & 31.3 & 35.2 & 44.9 & 43.2 & 58.2 & 51.1 & 33.7 & 40.6 \\
\hline $51-60$ & 33.5 & 28.0 & 35.8 & 35.7 & 44.3 & 46.9 & 31.3 & 37.3 & 40.3 & 34.5 \\
\hline$>60$ & 25.7 & 21.0 & 12.3 & 11.5 & 6.2 & 6.6 & 2.5 & 4.3 & 11.4 & 6.4 \\
\hline Vietnam era cohort ${ }^{+}$ & 69.6 & 57.3 & 58.1 & 56.6 & 68.1 & 70.8 & 50.1 & 57.8 & 62.3 & 53.2 \\
\hline Female $e^{\ddagger}$ & 11.7 & 2.6 & 9.2 & 2.1 & 6.6 & 2.4 & 2.5 & 2.8 & 4.7 & 2.3 \\
\hline Race African American & 54.5 & 64.6 & 56.2 & 54.5 & 63.0 & 66.6 & 79.6 & 80.4 & 56.4 & 53.0 \\
\hline Hispanic/other ${ }^{\dagger \ddagger}$ & 14.2 & 12.3 & 15.0 & 11.7 & 15.0 & 16.0 & 9.1 & 10.4 & 13.7 & 15.4 \\
\hline Married/living with partner & 47.2 & 24.4 & 45.0 & 23.2 & 36.8 & 25.5 & 21.6 & 13.9 & 39.8 & 28.8 \\
\hline Education $\leq$ high school $^{\dagger}$ & 38.8 & 35.7 & 37.8 & 33.9 & 38.6 & 42.8 & 46.0 & 49.9 & 42.4 & 31.6 \\
\hline Income $\geq \$ \overline{2} 5,000$ & 42.8 & 31.0 & 45.3 & 34.3 & 28.0 & 20.7 & 13.0 & 10.9 & 31.0 & 28.3 \\
\hline IVD past year & 0.6 & 0.8 & 0 & 0.7 & 2.9 & 2.2 & 19.8 & 27.1 & 1.2 & 0.8 \\
\hline Ever IVD & 3.0 & 8.3 & 0.5 & 2.1 & 31.3 & 66.0 & 42.3 & 57.9 & 10.8 & 21.0 \\
\hline Last injection heroin & 0.8 & 2.6 & 0 & 0.2 & 8.2 & 20.5 & 22.5 & 30.9 & 3.2 & 4.5 \\
\hline Last injection cocaine & 0.3 & 1.7 & 0 & 0.5 & 6.6 & 18.4 & 12.4 & 22.8 & 2.6 & 5.5 \\
\hline Past month worry about food & 15.3 & 14.0 & 14.3 & 19.2 & 23.8 & 22.3 & 40.6 & 39.5 & 27.2 & 22.6 \\
\hline Ever homeless & 19.6 & 26.6 & 20.1 & 27.2 & 61.0 & 62.7 & 83.1 & 77.6 & 45.3 & 35.1 \\
\hline Homelessness, past month & 2.9 & 2.3 & 2.4 & 3 & 11.7 & 3.7 & 40.0 & 22.1 & 6.4 & 2.7 \\
\hline \multicolumn{11}{|c|}{ Concurrent substance use, mental health, and treatment (\%) } \\
\hline Ever smoked & 58.5 & 56.1 & 68.3 & 69.5 & 85.0 & 90.6 & 89.1 & 91.4 & 79.2 & 76.4 \\
\hline Smokes currently & 25.4 & 28.4 & 31.5 & 38.7 & 53.7 & 55.5 & 77.1 & 81.6 & 51.5 & 49.5 \\
\hline Alcohol use $^{*}$ & 61.3 & 58.6 & 74.6 & 74.6 & 46.3 & 38.9 & 83.9 & 80.8 & 79.2 & 84.0 \\
\hline AUDIT-C score, median (IQR) & $1(3)$ & $1(3)$ & $2(3)$ & $2(2)$ & $2(4)$ & $2(4)$ & $3(6)$ & $3(5)$ & $3(4)$ & $2(3)$ \\
\hline Substance abuse treatment ${ }^{*}$ & 3.0 & 3.6 & 2.9 & 2.3 & 19.6 & 15.5 & 60.0 & 39.2 & 3.5 & 0.4 \\
\hline Methadone maintenance treatment ${ }^{*}$ & 0.3 & 1.1 & $0 \%$ & 0.2 & 5.1 & 6.6 & 20.8 & 11.6 & 0.3 & 0 \\
\hline Psychiatric disease cluster & 17.6 & 13.6 & 17.9 & 14.3 & 36.3 & 30.3 & 46.6 & 34.8 & 25.1 & 19.3 \\
\hline Schizophrenia & 5.0 & 2.6 & 4.1 & 1.2 & 7.9 & 6.1 & 10.1 & 6.7 & 5.3 & 1.7 \\
\hline Major depression, bipolar & 9.9 & 11.1 & 9.9 & 11.7 & 22.7 & 18.3 & 35.2 & 27.1 & 16.7 & 14.8 \\
\hline Post traumatic stress disorder & 8.2 & 4.3 & 7.7 & 3.8 & 17.9 & 12.7 & 21.0 & 11.0 & 11.4 & 4.5 \\
\hline SF-12_Mental composite, median (IQR) & $53.6(15.3)$ & $52.1(15.5)$ & $55.3(14.5)$ & $51.5(17.7)$ & $47.5(20.2)$ & $48.6(16.7)$ & $41.5(18.8)$ & $43.6(18.0)$ & $48.8(18.9)$ & $45.9(18.7)$ \\
\hline Mental health treatment ${ }^{*}$ & 21.4 & 19.1 & 22.8 & 19.9 & 45.0 & 33.8 & 73.2 & 45.6 & 29.5 & 21.0 \\
\hline \multicolumn{11}{|l|}{ Physical and medical conditions (\%) } \\
\hline BMI categories Obese & 42.0 & 15.7 & 41.0 & 11.3 & 43.5 & 20.1 & 32.0 & 9.4 & 37.7 & 8.8 \\
\hline Overweight ${ }^{\dagger \ddagger}$ & 37.5 & 38.0 & 41.2 & 42.0 & 33.3 & 37.1 & 37.8 & 33.8 & 36.0 & 34.9 \\
\hline 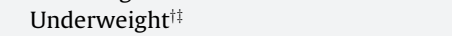 & 1.2 & 4.2 & 1.2 & 2.8 & 0.9 & 2.6 & 1.9 & 4.1 & 1.5 & 5.1 \\
\hline
\end{tabular}




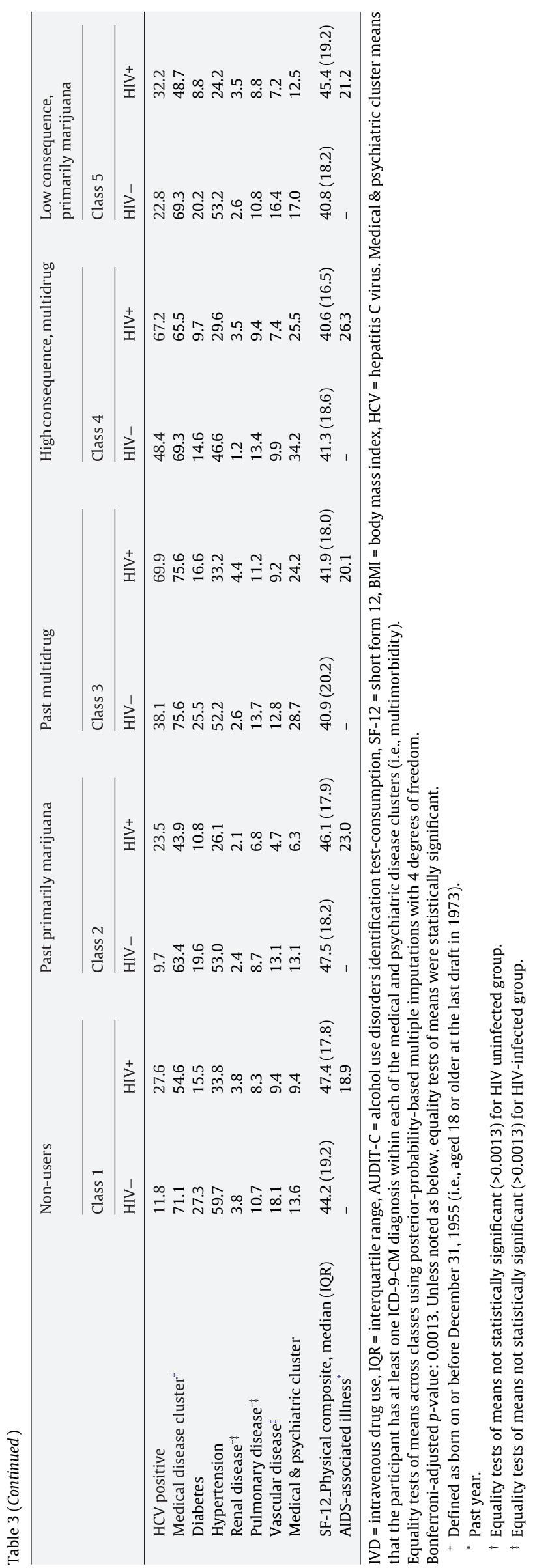

prevalences reported for class 1 and 2. For the HIV uninfected, socio-demographics (e.g., employment, history of homelessness, educational status) and high AUDIT-C scores were more akin to those of multidrug users (class 3,4). Past year alcohol use was reported by approximately $80 \%$ of this class and, generally, members were less likely to have been treated recently for substance abuse.

Regarding health status, the HIV-infected in class 5 had the lowest prevalence of obesity and a (non significant) high prevalence of being underweight. In contrast, prevalence of obesity was similar among the HIV uninfected in this class to those not currently using drugs. The HIV uninfected had lower physical than mental quality of life composite scores. Regardless of HIV status, class 5 exhibited poor quality of life on the SF-12 mental composite akin to current multidrug users yet unlike them receipt of mental health treatment was low. Medical and psychiatric disease prevalence in the HIV uninfected fell between those of classes 1, 2 and of 3, 4. A lower prevalence of AIDS-associated illness and medical and psychiatric disease was associated with this class's HIV-infected, in line with or lower than classes of users without a history of multidrug use.

Taken together, the Tables 2 and 3 data suggested that, more than a year ago, some of class 5 members transitioned away from hard drug use (i.e., HIV-, HIV+: $0.16,0.21$ probability of past heroin/opioid, $0.32,0.43$ past cocaine/stimulant) and injecting (i.e., $1.2 \%, 0.8 \%$ current injecting, $10.8 \%, 21.0 \%$ history of injecting) to primarily marijuana use. Other responses (e.g., never use) suggested initiation or continued use of primarily marijuana.

\section{Discussion}

This study used LCA to discover subpopulations of drug users and latent class regression to explicitly incorporate the influence of HIV status on their composition. We observed considerable drug use among an older adult population, one which is often not recognized as HIV-infected or drug using (Bhavan et al., 2008; Effros et al., 2008; Goulet et al., 2007; Hartel et al., 2006). A table in the online Appendix $\mathrm{A}^{1}$ summarizes the findings including similarities among classes, distinguishing characteristics, and HIV-specific results.

The continued drug use and specific patterns detected in our sample extend findings reported from other studies of aging, drug use, and HIV (Hartel et al., 2006; Hser et al., 2001; Lieberman, 2000; Pitts et al., 2005; Rosenberg, 1995; Schlaerth, 2007; Schlaerth et al., 2004). Similarities in drug use of HIV-infected and uninfected populations exist, suggesting that the general medicine clinic controls match well to the HIV-infected. However, key differences by HIV status emerged from this analysis, with clinical and public health implications for HIV and aging populations.

We found that drug use and abuse were lower but not uncommon among those of older ages, with illness, or even with HIV. These findings reinforce the need for age-appropriate treatment and harm reduction services and for physicians and caregivers to continue screening for substance abuse and dependence, regardless of their patient's age or disease status. Health maintenance guidelines for geriatric care (e.g., http://www.americangeriatrics.org) and for people aging with HIV make limited mention of substance abuse screening (Bhavan et al., 2008).

Within the HIV-infected and uninfected in the VACS, psychiatric comorbidities, medical comorbidities, and their co-occurrence were more prevalent in people with current and past histories of multidrug use but were far less prevalent among current primarily marijuana users. The "multimorbidity" among Veterans with HIV

\footnotetext{
1 Appendix - A summary of results is available as a table with the online version of this article at doi:10.1016/j.drugalcdep.2010.02.020.
} 
Table 4

Variables independently associated with class membership, latent class analysis with covariates results stratified by HIV status (reference=Class 1, non-users)

\begin{tabular}{|c|c|c|c|c|c|c|c|c|}
\hline & \multicolumn{2}{|c|}{$\begin{array}{l}\text { Past, primarily marijuana } \\
\text { Class } 2\end{array}$} & \multicolumn{2}{|l|}{$\begin{array}{l}\text { Past multidrug } \\
\text { Class } 3\end{array}$} & \multicolumn{2}{|c|}{$\begin{array}{l}\text { High consequence, multidrug } \\
\text { Class } 4\end{array}$} & \multicolumn{2}{|c|}{$\begin{array}{l}\text { Low consequence, primarily marijuana } \\
\text { Class } 5\end{array}$} \\
\hline & HIV- & HIV+ & HIV- & HIV+ & HIV- & HIV+ & HIV- & HIV+ \\
\hline Age $(\mathrm{ref}=41-50) \leq 40$ & $\begin{array}{l}1.14 \\
(0.78,1.65)\end{array}$ & $\begin{array}{l}0.74 \\
(0.49,1.11)\end{array}$ & $\begin{array}{l}0.41 \\
(0.24,0.70)\end{array}$ & $\begin{array}{l}0.28 \\
(0.14,0.54)\end{array}$ & $\begin{array}{l}0.49 \\
(0.29,0.85)\end{array}$ & $\begin{array}{l}0.54 \\
(0.32,0.90)\end{array}$ & $\begin{array}{l}1.45 \\
(0.72,1.81)\end{array}$ & $\begin{array}{l}0.76 \\
(0.52,1.12)\end{array}$ \\
\hline $51-60$ & $\begin{array}{l}0.76 \\
(0.55,1.04)\end{array}$ & $\begin{array}{l}1.07 \\
(0.75,1.53)\end{array}$ & $\begin{array}{l}0.60 \\
(0.44,0.82)\end{array}$ & $\begin{array}{l}0.85 \\
(0.59,1.21)\end{array}$ & $\begin{array}{l}0.31 \\
(0.19,0.50)\end{array}$ & $\begin{array}{l}0.60 \\
(0.40,0.90)\end{array}$ & $\begin{array}{l}0.79 \\
(0.55,1.13)\end{array}$ & $\begin{array}{l}0.82 \\
(0.58,1.15)\end{array}$ \\
\hline$>60$ & $\begin{array}{l}0.29 \\
(0.18,0.45)\end{array}$ & $\begin{array}{l}0.38 \\
(0.24,0.61)\end{array}$ & $\begin{array}{l}0.18 \\
(0.11,0.30)\end{array}$ & $\begin{array}{l}0.33 \\
(0.18,0.59)\end{array}$ & $\begin{array}{l}0.11 \\
(0.03,0.37)\end{array}$ & $\begin{array}{l}0.25 \\
(0.12,0.51)\end{array}$ & $\begin{array}{l}0.36 \\
(0.21,0.61)\end{array}$ & $\begin{array}{l}0.21 \\
(0.12,0.36)\end{array}$ \\
\hline African American & $\begin{array}{l}1.11 \\
(0.83,1.49)\end{array}$ & $\begin{array}{l}0.53 \\
(0.38,0.74)\end{array}$ & $\begin{array}{l}1.30 \\
(0.94,1.80)\end{array}$ & $\begin{array}{l}1.13 \\
(0.73,1.76)\end{array}$ & $\begin{array}{l}2.90 \\
(1.62,5.19)\end{array}$ & $\begin{array}{l}3.06 \\
(1.59,5.90)\end{array}$ & $\begin{array}{l}1.09 \\
(0.77,1.54)\end{array}$ & $\begin{array}{l}0.63 \\
(0.45,0.88)\end{array}$ \\
\hline Hispanic/other & $\begin{array}{l}1.00 \\
(0.66,1.50)\end{array}$ & $\begin{array}{l}0.59 \\
(0.36,0.97)\end{array}$ & $\begin{array}{l}1.20 \\
(0.78,1.85)\end{array}$ & $\begin{array}{l}1.36 \\
(0.78,2.36)\end{array}$ & $\begin{array}{l}1.22 \\
(0.57,2.63)\end{array}$ & $\begin{array}{l}1.91 \\
(0.91,4.03)\end{array}$ & $\begin{array}{l}0.87 \\
(0.54,1.40)\end{array}$ & $\begin{array}{l}0.83 \\
(0.52,1.34)\end{array}$ \\
\hline Currently employed & $\begin{array}{l}0.82 \\
(0.62,1.08)\end{array}$ & $\begin{array}{l}0.98 \\
(0.71,1.34)\end{array}$ & $\begin{array}{l}0.98 \\
(0.70,1.31)\end{array}$ & $\begin{array}{l}0.85 \\
(0.59,1.21)\end{array}$ & $\begin{array}{l}0.51 \\
(0.33,0.79)\end{array}$ & $\begin{array}{l}0.47 \\
(0.32,0.71)\end{array}$ & $\begin{array}{l}0.60 \\
(0.44,0.83)\end{array}$ & $\begin{array}{l}0.72 \\
(0.52,0.99)\end{array}$ \\
\hline Alcohol use past year & $\begin{array}{l}1.51 \\
(1.10,2.06)\end{array}$ & $\begin{array}{l}2.06 \\
(1.44,2.96)\end{array}$ & $\begin{array}{l}0.52 \\
(0.37,0.73)\end{array}$ & $\begin{array}{l}0.52 \\
(0.35,0.77)\end{array}$ & $\begin{array}{l}3.16 \\
(1.86,5.39)\end{array}$ & $\begin{array}{l}2.99 \\
(1.91,4.70)\end{array}$ & $\begin{array}{l}1.87 \\
(1.30,2.70)\end{array}$ & $\begin{array}{l}3.65 \\
(2.55,5.22)\end{array}$ \\
\hline AUDIT-C score & $\begin{array}{l}1.04 \\
(0.97,1.11)\end{array}$ & $\begin{array}{l}1.03 \\
(0.95,1.12)\end{array}$ & $\begin{array}{l}1.13 \\
(1.06,1.20)\end{array}$ & $\begin{array}{l}1.18 \\
(1.09,1.27)\end{array}$ & $\begin{array}{l}1.16 \\
(1.07,1.25)\end{array}$ & $\begin{array}{l}1.20 \\
(1.10,1.30)\end{array}$ & $\begin{array}{l}1.13 \\
(1.06,1.21)\end{array}$ & $\begin{array}{l}1.08 \\
(1.01,1.15)\end{array}$ \\
\hline Ever smoked & $\begin{array}{l}1.92 \\
(1.39,2.66)\end{array}$ & $\begin{array}{l}1.93 \\
(1.34,2.79)\end{array}$ & $\begin{array}{l}2.56 \\
(1.73,3.80)\end{array}$ & $\begin{array}{l}2.85 \\
(1.78,4.57)\end{array}$ & $\begin{array}{l}1.66 \\
(0.90,3.07)\end{array}$ & $\begin{array}{l}1.57 \\
(0.84,2.94)\end{array}$ & $\begin{array}{l}1.92 \\
(1.29,2.86)\end{array}$ & $\begin{array}{l}2.13 \\
(1.46,3.10)\end{array}$ \\
\hline Smokes currently & $\begin{array}{l}0.84 \\
(0.61,1.16)\end{array}$ & $\begin{array}{l}1.00 \\
(0.69,1.44)\end{array}$ & $\begin{array}{l}1.12 \\
(0.82,1.53)\end{array}$ & $\begin{array}{l}1.59 \\
(1.08,2.33)\end{array}$ & $\begin{array}{l}1.82 \\
(1.10,2.99)\end{array}$ & $\begin{array}{l}3.57 \\
(2.20,5.81)\end{array}$ & $\begin{array}{l}1.45 \\
(1.01,2.07)\end{array}$ & $\begin{array}{l}1.27 \\
(0.88,1.82)\end{array}$ \\
\hline Ever homeless & $1.18(0.80,1.72)$ & $\begin{array}{l}0.89 \\
(0.61,1.28)\end{array}$ & $\begin{array}{l}2.96 \\
(2.19,4.01)\end{array}$ & $\begin{array}{l}2.21 \\
(1.56,3.11)\end{array}$ & $\begin{array}{l}4.22 \\
(2.66,6.71)\end{array}$ & $\begin{array}{l}3.36 \\
(2.02,5.61)\end{array}$ & $\begin{array}{l}2.58 \\
(1.84,3.65)\end{array}$ & $\begin{array}{l}1.11 \\
(0.81,1.52)\end{array}$ \\
\hline Past mo homeless & $\begin{array}{l}0.81 \\
(0.36,1.81)\end{array}$ & $\begin{array}{l}1.48 \\
(0.57,3.89)\end{array}$ & $\begin{array}{l}1.29 \\
(0.74,2.23)\end{array}$ & $\begin{array}{l}0.78 \\
(0.33,1.85)\end{array}$ & $\begin{array}{l}2.86 \\
(1.58,5.17)\end{array}$ & $\begin{array}{l}2.81 \\
(1.27,6.21)\end{array}$ & $\begin{array}{l}0.65 \\
(0.31,1.35)\end{array}$ & $\begin{array}{l}1.03 \\
(0.37,2.85)\end{array}$ \\
\hline Past mo worry about food & $\begin{array}{l}0.87 \\
(0.58,1.31)\end{array}$ & $\begin{array}{l}1.49 \\
(1.00,2.22)\end{array}$ & $\begin{array}{l}0.89^{\mathrm{a}} \\
(0.61,1.32)\end{array}$ & $\begin{array}{l}1.17 \\
(0.78,1.75)\end{array}$ & $\begin{array}{l}1.32 \\
(0.85,2.06)\end{array}$ & $\begin{array}{l}1.82 \\
(1.19,2.78)\end{array}$ & $\begin{array}{l}1.16 \\
(0.80,1.68)\end{array}$ & $\begin{array}{l}1.38 \\
(0.94,2.03)\end{array}$ \\
\hline IVD past yr & $\begin{array}{l}0.30 \\
(0.002,47.42)\end{array}$ & $\begin{array}{l}1.46 \\
(0.31,6.76)\end{array}$ & $\begin{array}{l}1.37 \\
(0.51,3.70)\end{array}$ & $\begin{array}{l}0.59 \\
(0.16,2.10)\end{array}$ & $\begin{array}{l}7.67 \\
(2.96,19.84)\end{array}$ & $\begin{array}{l}12.26 \\
(3.68,40.87)\end{array}$ & $\begin{array}{l}1.40 \\
(0.36,5.42)\end{array}$ & $\begin{array}{l}0.53 \\
(0.11,2.51)\end{array}$ \\
\hline Ever IVD & $\begin{array}{l}0.16 \\
(0.02,1.33)\end{array}$ & $\begin{array}{l}0.39 \\
(0.14,1.05)\end{array}$ & $\begin{array}{l}7.61 \\
(4.57,12.65)\end{array}$ & $\begin{array}{l}11.61 \\
(7.66,17.59)\end{array}$ & $\begin{array}{l}9.43 \\
(4.99,17.80)\end{array}$ & $\begin{array}{l}7.29 \\
(4.35,12.24)\end{array}$ & $\begin{array}{l}2.72 \\
(1.50,4.93)\end{array}$ & $\begin{array}{l}2.94 \\
(1.88,4.57)\end{array}$ \\
\hline SF-12 mental composite score & $\begin{array}{l}1.01 \\
(0.99,1.02)\end{array}$ & $\begin{array}{l}1.00 \\
(0.99,1.02)\end{array}$ & $\begin{array}{l}0.99 \\
(0.98,1.00)\end{array}$ & $\begin{array}{l}0.99 \\
(0.97,1.01)\end{array}$ & $\begin{array}{l}0.97 \\
(0.96,0.99)\end{array}$ & $\begin{array}{l}0.99 \\
(0.97,1.00)\end{array}$ & $\begin{array}{l}0.99 \\
(0.97,1.00)\end{array}$ & $\begin{array}{l}0.98 \\
(0.97,0.99)\end{array}$ \\
\hline Past year SA treatment & $1.14(0.52,2.47)$ & $0.66(0.21,2.11)$ & $3.75(2.23,6.30)$ & $2.18(1.12,4.23)$ & $17.91(9.91,32.39)$ & $5.55(2.80,11.00)$ & $0.98(0.39,2.46)$ & $0.18(0.04,0.92)$ \\
\hline BMI (ref= normal) Obese & - & $\begin{array}{l}0.70 \\
(0.45,1.11)\end{array}$ & - & $\begin{array}{l}1.54 \\
(0.98,2.41)\end{array}$ & - & $\begin{array}{l}0.63 \\
(0.38,1.05)\end{array}$ & - & $\begin{array}{l}0.47 \\
(0.30,0.74)\end{array}$ \\
\hline Overweight & - & $\begin{array}{l}1.12 \\
(0.83,1.52)\end{array}$ & - & $\begin{array}{l}1.07 \\
(0.75,1.52)\end{array}$ & - & $\begin{array}{l}0.78 \\
(0.54,1.15)\end{array}$ & - & $\begin{array}{l}0.81 \\
(0.60,1.09)\end{array}$ \\
\hline Underweight & - & $\begin{array}{l}0.62 \\
(0.27,1.41)\end{array}$ & - & $\begin{array}{l}0.68 \\
(0.31,1.53)\end{array}$ & - & $\begin{array}{l}0.57 \\
(0.21,1.61)\end{array}$ & - & $\begin{array}{l}0.90 \\
(0.42,1.93)\end{array}$ \\
\hline Married & - & $\begin{array}{l}0.83 \\
(0.59,1.15)\end{array}$ & - & $\begin{array}{l}0.77 \\
(0.53,1.13)\end{array}$ & - & $\begin{array}{l}0.48 \\
(0.31,0.75)\end{array}$ & - & $\begin{array}{l}1.04 \\
(0.76,1.43)\end{array}$ \\
\hline Sex (1 = female $)$ & $\begin{array}{l}0.64 \\
(0.41,1.00)\end{array}$ & - & $\begin{array}{l}0.55 \\
(0.34,0.91)\end{array}$ & - & $\begin{array}{l}0.18 \\
(0.07,0.46)\end{array}$ & - & $\begin{array}{l}0.37 \\
(0.20,0.68)\end{array}$ & - \\
\hline
\end{tabular}

Adjusted odds ratios and (95\% confidence intervals). Reference class = non-users, Class 1.

Model is adjusted for all other significant covariates detected in multinomial regressions using the unadjusted LCA class results.

- = no estimate because variable not included in model.

$\mathrm{SA}=$ substance abuse, including alcohol and/or drug abuse, BMI = body mass index, IVD = intravenous drug use, AUDIT-C = alcohol use disorders identification test-consumption, $\mathrm{SF}-12$ = short form 12

Bold values are statistically significant from the reference non-user class within HIV status. 
and substance use disorder has been described previously (Goulet et al., 2007). Our results expand upon this work by highlighting the heterogeneity and range of multimorbidity by pattern of drug use. This study did not capture severity of comorbidities, however, for similar prevalences of medical and psychiatric comorbidity diagnoses, members of the current multidrug users class reported the lowest physical and mental quality of life scores. In addition, AIDS-associated illness was highest in the current multidrug users class. Results suggest that effectively treating the older adult HIVinfected patient in the VA, as elsewhere, will entail addressing multimorbidities as well as employing special efforts such as interventions to improve medication adherence and reduce depressive symptoms (Altice et al., 2007, 2004; Safren et al., 2009), to keep AIDS-associated illness at bay in older adults who continue multidrug use.

The low consequence, primarily marijuana users appear to be a unique drug-using group. The low prevalence of drug dependence and the absence of negative consequences despite chronic use runs counter to research on cannabis abuse/dependence and their subtypes (Grant et al., 2006). However, other LCA studies have detected the existence of a marijuana-only drug use class amongst nationally representative samples of lifetime drug users (Agrawal et al., 2007). Motivations for primarily marijuana use may be a mixture of transitions away from use of other drugs, (re)initiation, self-medication, or evidence of diffusion of medical marijuana as innovative treatment (e.g., appetite stimulation, management of medication side effects (de Jong et al., 2005; Haney et al., 2007; Kuo et al., 2004)), which might be better known to the HIV community and their physicians. Whether this class represents a later stage of drug use, as suggested by similarities to the multidrug user classes for the HIV uninfected, a therapeutic disease-specific class, as suggested by similarities to the non-user and past marijuana users for the HIV-infected, or if differences indicate two separate pathways into this class, is open for inquiry.

The discovered classes appear to be valid, as indicated by the association between the clinical diagnostic criteria in the expected directions and by the covariates predictive of class membership. For example, one would have expected, as was found, that recent injecting drug use would be strongly related to the high consequence, multidrug users (class 4 ) but not to any other class. Adjusting for covariates improved our models' fit, aligning results closer to the true class membership and highlighting the interplay of predisposing (e.g., race, gender, homelessness), enabling (e.g., income, education), and need (e.g., comorbidities) factors expected under Gelberg's Behavioral Model for Vulnerable Populations (Gelberg et al., 2000). Other reported LCAs of drug abuse (e.g., (Agrawal et al., 2007; Monga et al., 2007) have not adjusted for covariates.

Some of our findings concur with previously reported LCAs, which detected classes of marijuana-only and multidrug users (Agrawal et al., 2007), while there are also some classes we could not detect, such as prescription drug abusers. Differences may be explained by choice of study sample (age, illness status), exposure assessment (lifetime versus past year use, types of drugs assessed), choice of model (dichotomous, ordinal, etc.), and inclusion of covariates, among others.

Future studies should explore longitudinal transitions between classes and test hypotheses about class membership. Little is known about how frequently older HIV-infected and uninfected drug users move in and out of treatment, initiate and terminate drug use, and switch to other substances (Hser et al., 2007). It has been hypothesized that the increasing isolation experienced as one ages may promote transitions from "harder" drugs (e.g., heroin) which may be used alone to "softer" drugs (e.g., marijuana) used more socially (Fogarty et al., 2007; Osborne and Fogel, 2008; Schlaerth et al., 2004). Future endeavors should also test the utility and validity of our derived drug use classes in predicting key health outcomes.

This study has several limitations. The crucial limitation is its cross-sectional nature. One cannot conclude from our data, for example, that drug use decreases with increasing age but rather that, at the ages represented in VACS, probability of certain class membership is lower at older ages. In cross-sectional designs, it is also not possible to determine whether the classes of current and past drug users are stable or dynamic, whether they represent switching of substances or harm minimizing use, intensification or diminution of particular substances used over time, or whether members are incident, chronic prevalent or relapse case members. Longitudinal analyses are underway to address such questions. In the meantime, this study presents hypothesis-generating, initial descriptions and comparisons by HIV status of an aging, considerably active drug-using population. Also, VACS focuses on an aging population, thus our study may not be representative of young HIVinfected Veterans and women, who could have different drug use patterns. The largely male older Veteran population of the VACS may also not be representative of aging adults more generally. However, drug use in older adults occurs predominantly among males (Armstrong, 2007; Han et al., 2009a; Zanjani et al., 2007) and the high degree of drug use found in the VACS HIV uninfected population shares similarities with use among older people in the general population described by others (Han et al., 2009b). Prevalence of club drug and benzodiazepine use was not assessed, hence we may have underestimated the true prevalence of drug use. Prescription opioid abuse was not measured separately from heroin so any potential transition to these substances would not be detected in item-response probabilities. Finally, the extent to which our findings generalize to non-Veterans is unknown. While Veterans in care generally differ substantially from the US population receiving health care, Veterans in care with HIV infection have much in common with others receiving treatment for HIV infection (Conigliaro et al., 2006; Kohli et al., 2005; Lohse et al., 2007; Palella et al., 2006). As evidence of this fact, VACS data was directly compared to other large HIV cohorts in Europe and North America and deemed consistent enough with these other samples to be combined in two high profile cross cohort analyses (Kitahata et al., 2009; Sterne et al., 2009).

The prevalence of any current drug use (classes 4 and 5) in the VACS was $44.5 \%$ among HIV-infected and 30\% among HIV uninfected. Relying on clinical reports of drug dependence would instead place the estimate at $25 \%$ (ICD-9 code) or $14 \%$ (CIDI-SF), with no statistical differences by HIV status. Moreover, there was substantial divergence between EMR and self-reported data (CIDI-SF or LCA) for the past multidrug user class, implying misclassification of past users as current users in the EMR. An LCA approach to exposure measurement serves as a descriptive and analytic tool to find consensus in patterns of behavior reported by participants in a way that incorporates rather than punishes for measurement error and missing data typical in observational study. As the application of LCA continues to expand (Muthen, 1992, 2008), our study suggests that LCA can be used to detect statistically and clinically valid subpopulations of drug users without having to administer lengthy interviews or having to rely solely on medical record-generated proxies of drug abuse/dependence.

Our findings contribute to the increasing literature on drug use, aging, and HIV (Bhavan et al., 2008; Effros et al., 2008; Ettenhofer et al., 2009; Han et al., 2009a,b) and are directly relevant to the VA, which provides treatment and care to more than 19,000 people with HIV and 213,000 people diagnosed with Substance Abuse Disorders as well as to Veterans with undetected diagnoses. Specifically, intervention should be prioritized for the problematic multidrug user class, who showed considerable need, poor health, and low quality of life. Results lend support for efforts to inte- 
grate mental health, chronic disease, and HIV care; implementation of screening for improved detection of drug abuse and potential referral for specialized care; and expansion of age-appropriate treatment and harm reduction options for drug users.

\section{Role of Funding Source}

Research for this manuscript was supported by the National Institutes of Health, National Institute on Drug Abuse grant 1F31DA023862-01A1 to TCG. The Veterans Aging Cohort Study funded by: National Institute on Alcohol Abuse and Alcoholism (U10 AA 13566) and VHA Public Health Strategic Health Core Group. The funding sources had no further involvement in the study design, data collection, analysis, writing, preparation or decision to submit this manuscript for publication.

\section{Contributors}

TCG conceived of the analysis, conducted the statistical analysis, and authored the first manuscript draft; TK, HL, JG, KK, AG, $\mathrm{RH}, \mathrm{DF}$ and $\mathrm{AJ}$ guided interpretation of analyses and provided comments to manuscript drafts; ND, SM, and KB provided comments to manuscript drafts. All authors contributed to and have approved the final manuscript.

\section{Conflict of Interest}

All authors declare that they have no conflicts of interest.

\section{Acknowledgements}

We wish to thank Kristin Mattocks, Melissa Skanderson, and Cynthia Brandt for their assistance in data management and preparation. We are grateful to the VACS participants and the research sites and staff coordinating this study.

\section{Appendix A. Supplementary data}

Supplementary data associated with this article can be found, in the online version, at doi:10.1016/j.drugalcdep.2010.02.020.

\section{References}

AETC, 2006. Recreational drugs and antiretroviral therapy. Clinical Manual for Management of the HIV-Infected Adult. AIDS Education and Training Center, Newark, NJ.

Agrawal, A., Lynskey, M.T., Madden, P.A., Bucholz, K.K., Heath, A.C., 2007. A latent class analysis of illicit drug abuse/dependence: results from the National Epidemiological Survey on Alcohol and Related Conditions. Addiction (Abingdon, England) 102, 94-104.

Altice, F.L., Maru, D.S., Bruce, R.D., Springer, S.A., Friedland, G.H., 2007. Superiority of directly administered antiretroviral therapy over self-administered therapy among HIV-infected drug users: a prospective, randomized, controlled trial. Clinical Infectious Disease 45, 770-778.

Altice, F.L., Mezger, J.A., Hodges, J., Bruce, R.D., Marinovich, A., Walton, M., Springer, S.A., Friedland, G.H., 2004. Developing a directly administered antiretroviral therapy intervention for HIV-infected drug users: implications for program replication. Clinical Infectious Disease 38 (Suppl. 5), S376-S387.

Armstrong, G.L., 2007. Injection Drug Users in the United States, 1979-2002: An Aging Population. Archives of Internal Medicine 167, 166-173.

Bhavan, K.P., Kampalath, V.N., Overton, E.T., 2008. The aging of the HIV epidemic. Current HIV/AIDS Reports 5, 150-158.

Bruce, R.D., Altice, F.L., Friedland, G.H., 2008. Pharmacokinetic drug interactions between drugs of abuse and antiretroviral medications: implications and management for clinical practice. Journal of Acquired Immune Deficiency Syndromes 41, 563-572.

Bush, K., Kivlahan, D.R., McDonell, M.B., Fihn, S.D., Bradley, K.A., 1998. The AUDIT alcohol consumption questions (AUDIT-C): an effective brief screening test for problem drinking, ambulatory care quality improvement project (ACQUIP). Alcohol Use Disorders Identification Test. Archives of Internal Medicine 158, 1789-1795.
Centers for Disease Control and Prevention, 1993. 1993 revised classification system for HIV infection and expanded surveillance case definition for AIDS among adolescents and adults. Journal of the American Medical Association 269, 729-730.

Centers for Disease Control and Prevention, 2002. Core measures for HIV/STD risk behavior and prevention. Sexual Behavior and Drug Behavior Questions, Versions 4 \& 5. Centers for Disease Control and Prevention, Atlanta.

Centers for Disease Control and Prevention, 2008. Subpopulation estimates from the HIV incidence surveillance system - United States, 2006. Morbidity and Mortality Weekly Report 57, 985-989.

Centers for Disease Control and Prevention, 2009. HIV-associated behaviors among injecting-drug users - 23 cities, United States, May 2005-February 2006. Morbidity and Mortality Weekly Report 58, 329-332.

Colliver, J.D., Compton, W.M., Gfroerer, J.C., Condon, T., 2006. Projecting drug use among aging baby boomers in 2020. Annals of Epidemiology 16, 257-265.

Conigliaro, J., Justice, A.C., Gordon, A.J., Bryant, K., 2006. Role of alcohol in determining human immunodeficiency virus (HIV)-relevant outcomes: a conceptual model to guide the implementation of evidence-based interventions into practice. Medical Care 44, S1-S6.

Conigliaro, J., Madenwald, T., Bryant, K., Braithwaite, S., Gordon, A., Fultz, S.L., Maisto S., Samet, J., Kraemer, K., Cook, R., Day, N., Roach, D., Richey, S., Justice, A., 2004 The veterans aging cohort study: observational studies of alcohol use, abuse, and outcomes among human immunodeficiency virus-infected veterans. Alcoholism, Clinical and Experimental Research 28, 313-321.

Darke, S., Zador, D., 1996. Fatal Heroin 'Overdose’: A Review, pp. 1765-1772.

de Jong, B.C.M.D., Prentiss, D.M.A.M.P.H., McFarland, W.M.D.P., Machekano, R.M.P.H Israelski, D.M.M.D., 2005. Marijuana use and its association with adherence to antiretroviral therapy among HIV-infected persons with moderate to severe nausea. Journal of Acquired Immune Deficiency Syndromes 38, 43-46.

Delucchi, K.L., Matzger, H., Weisner, C., 2004. Dependent and problem drinking over 5 years: a latent class growth analysis. Drug Alcohol Depend 74, 235-244.

Des Jarlais, D.C., Marmor, M., Friedmann, P., Titus, S., Aviles, E., Deren, S., Torian, L., Glebatis, D., Murrill, C., Monterroso, E., Friedman, S.R., 2000. HIV incidence among injection drug users in New York City, 1992-1997: evidence for a declining epidemic. American Journal of Public Health 90, 352-359.

Druss, B.G., Rosenheck, R.A., 2000. Locus of mental health treatment in an integrated service system. Psychiatric Services (Washington, DC) 51, 890-892.

Effros, R.B., Fletcher, C.V., Gebo, K., Halter, J.B., Hazzard, W.R., Horne, F.M., Huebner R.E., Janoff, E.N., Justice, A.C., Kuritzkes, D., Nayfield, S.G., Plaeger, S.F., Schmader, K.E., Ashworth, J.R., Campanelli, C., Clayton, C.P., Rada, B., Woolard, N.F., High, K.P., 2008. Aging and infectious diseases: workshop on HIV infection and aging: what is known and future research directions. Clinical Infectious Diseases 47 542-553.

Ettenhofer, M.L., Hinkin, C.H., Castellon, S.A., Durvasula, R., Ullman, J., Lam, M., Myers, H., Wright, M.J., Foley, J., 2009. Aging, neurocognition, and medication adherence in HIV infection. American Journal of Geriatric Psychiatry 17, 281-290.

Fogarty, A., Rawstorne, P., Prestage, G., Crawford, J., Grierson, J., Kippax, S., 2007. Marijuana as Therapy for People Living with HIV/AIDS: Social and Health Aspects. Routledge, pp. 295-301.

Friedmann, P.D., McCullough, D., Saitz, R., 2001. Screening and intervention for illicit drug abuse: a national survey of primary care physicians and psychiatrists. Archives of Internal Medicine 161, 248-251.

Gelberg, L., Andersen, R.M., Leake, B.D., 2000. The behavioral model for vulnerable populations: application to medical care use and outcomes for homeless people. Health Services Research 34, 1273-1302.

Geriatric Mental Health Foundation, 2010. Substance Abuse and Misuse among Older Adults, http://www.gmhfonline.org/gmhf/consumer/factsheets/ substnabuse factsheet.html. Accessed on January 30, 2010.

Gfroerer, J., Penne, M., Pemberton, M., Folsom, R., 2003. Substance abuse treatment need among older adults in 2020: the impact of the aging baby-boom cohort Drug and Alcohol Dependence 69, 127-135.

Ghandour, L.A., Martins, S.S., Chilcoat, H.D., 2008. Understanding the patterns and distribution of opioid analgesic dependence symptoms using a latent empirical approach. International Journal of Methods in Psychiatric Research 17, 89-103.

Gordon, A.J., McGinnis, K.A., Conigliaro, J., Rodriguez-Barradas, M.C., Rabeneck, L., Justice, A.C., 2006. Associations between alcohol use and homelessness with healthcare utilization among human immunodeficiency virus-infected veterans. Medical Care 44, S37-S43.

Goulet, J.L., Fultz, S.L., McGinnis, K.A., Justice, A.C., 2005. Relative prevalence of comorbidities and treatment contraindications in HIV-mono-infected and HIV/HCV-co-infected veterans. AIDS 19 (Suppl. 3), S99-S105.

Goulet, J.L., Fultz, S.L., Rimland, D., Butt, A., Gibert, C., Rodriguez-Barradas, M., Bryant, K., Justice, A.C., 2007. Aging and infectious diseases: do patterns of comorbidity vary by HIV status, age, and HIV severity? Clinical Infectious Disease 45 1593-1601.

Grant, J.D., Scherrer, J.F., Neuman, R.J., Todorov, A.A., Price, R.K., Bucholz, K.K., 2006. A comparison of the latent class structure of cannabis problems among adult men and women who have used cannabis repeatedly. Addiction 101, 1133-1142.

Hagenaars, J.A., McCutcheon, A., 2002. Applied Latent Class Analysis. Cambridge University Press, Cambridge.

Han, B., Gfroerer, J.C., Colliver, J.D., 2009. An examination of trends in illicit drug use among adults aged 50-59 in the United States. OAS Data Review. Office of Applied Studies: Substance Abuse and Mental Health Services Administration, Rockville, MD.

Han, B., Gfroerer, J.C., Colliver, J.D., Penne, M.A., 2009b. Substance use disorder among older adults in the United States in 2020. Addiction (Abingdon, England) 104 88-96. 
Haney, M.P., Gunderson, E.W.M.D., Rabkin, J.P., Hart, C.L.P., Vosburg, S.K.P., Comer, S.D.P., Foltin, R.W.P., 2007. Dronabinol and marijuana in HIV-positive marijuana smokers: caloric intake, mood, and sleep. Journal of Acquired Immune Deficiency Syndromes 45, 545-554.

Hartel, D.M., Schoenbaum, E.E., Lo, Y., Klein, R.S., 2006. Gender differences in illicit substance use among middle-aged drug users with or at risk for HIV infection. Clinical Infectious Disease 43, 525-531.

Hser, Y.I., Hoffman, V., Grella, C.E., Anglin, M.D., 2001. A 33-year follow-up of narcotics addicts. Archives of General Psychiatry 58, 503-508.

Hser, Y.I., Longshore, D., Anglin, M.D., 2007. The life course perspective on drug use: a conceptual framework for understanding drug use trajectories. Evaluation Review 31, 515-547.

Justice, A.C., 2006. Prioritizing primary care in HIV: comorbidity, toxicity, and demography. Topics in HIV Medicine 14, 159-163.

Justice, A.C., Dombrowski, E., Conigliaro, J., Fultz, S.L., Gibson, D., Madenwald, T. Goulet, J., Simberkoff, M., Butt, A.A., Rimland, D., Rodriguez-Barradas, M.C., Gibert, C.L., Oursler, K.A., Brown, S., Leaf, D.A., Goetz, M.B., Bryant, K., 2006a. Veterans aging cohort study (VACS): overview and description. Medical Care 44, S13-S24.

Justice, A.C., Landefeld, C.S., Asch, S.M., Gifford, A.L., Whalen, C.C., Covinsky, K.E. 2001. Justification for a new cohort study of people aging with and without HIV infection. Journal of Clinical Epidemiology 54 (Suppl. 1), S3-S8.

Justice, A.C., Lasky, E., McGinnis, K.A., Skanderson, M., Conigliaro, J., Fultz, S.L. Crothers, K., Rabeneck, L., Rodriguez-Barradas, M., Weissman, S.B., Bryant, K., 2006b. Medical disease and alcohol use among veterans with human immunodeficiency infection: a comparison of disease measurement strategies. Medical Care 44, S52-S60.

Juurlink, D.N., Detsky, A.S., 2005. Kappa Statistic. Canadian Medical Association Journal 173,16 .

Kapadia, F., Vlahov, D., Donahoe, R.M., Friedland, G., 2005. The role of substance abuse in HIV disease progression: reconciling differences from laboratory and epidemiologic investigations. Clinical Infectious Disease 41 1027-1034.

Kessler, R.C., Andrews, G., Mroczek, D., Üstün, T.B., Wittchen, H.-U., 1998. The world health organization composite international diagnostic interview short form (CIDI-SF). International Journal of Methods in Psychiatric Research 7, $171-185$.

Kilbourne, A.M., Justice, A.C., Rabeneck, L., Rodriguez-Barradas, M., Weissman, S., 2001. General medical and psychiatric comorbidity among HIV-infected veterans in the post-HAART era. Journal of Clinical Epidemiology 54 (Suppl. 1), S22-S28

Kim, T.W., Kertesz, S.G., Horton, N.J., Tibbetts, N., Samet, J.H., 2006. Episodic homelessness and health care utilization in a prospective cohort of HIV-infected persons with alcohol problems. BMC Health Services Research 6, 19.

Kim, T.W., Samet, J.H., Cheng, D.M., Winter, M.R., Safran, D.G., Saitz, R., 2007. Primary care quality and addiction severity: a prospective cohort study. Health Services Research 42, 755-772.

Kitahata, M.M., Gange, S.J., Abraham, A.G., Merriman, B., Saag, M.S., Justice, A.C. Hogg, R.S., Deeks, S.G., Eron, J.J., Brooks, J.T., Rourke, S.B., Gill, M.J., Bosch, R.J., Martin, J.N., Klein, M.B., Jacobson, L.P., Rodriguez, B., Sterling, T.R., Kirk, G.D., Napravnik, S., Rachlis, A.R., Calzavara, L.M., Horberg, M.A., Silverberg, M.J., Gebo, K.A., Goedert, J.J., Benson, C.A., Collier, A.C., Van Rompaey, S.E., Crane, H.M., McKaig, R.G., Lau, B., Freeman, A.M., Moore, R.D., 2009. Effect of early versus deferred antiretroviral therapy for HIV on survival. The New England Journal of Medicine 360, 1815-1826.

Kohli, R., Lo, Y., Howard, A.A., Buono, D., Floris-Moore, M., Klein, R.S., Schoenbaum, E.E., 2005. Mortality in an urban cohort of HIV-infected and at-risk drug users in the era of highly active antiretroviral therapy. Clinical Infectious Disease 41 , 864-872.

Kral, A.H., Bluthenthal, R.N., Lorvick, J., Gee, L., Bacchetti, P., Edlin, B.R., 2001. Sexual transmission of HIV-1 among injection drug users in San Francisco, USA: riskfactor analysis. Lancet 357, 1397-1401.

Kuo, W.H., Wilson, T.E., Weber, K.M., Madhava, V., Richardson, J., Delapenha, R., Des Jarlais, D., 2004. Initiation of regular marijuana use among a cohort of women infected with or at risk for HIV in the Women's Interagency HIV Study (WIHS). AIDS Patient Care and STDs 18, 702-713.

Landis, J.R., Koch, G.G., 1977. The measurement of observer agreement for categorical data. Biometrics 33, 159-174.

Lee, L.M., McKenna, M., Sharpe, T.T., 2003. HIV diagnoses among injectiondrug users in states with HIV surveillance - 25 States, 1994-2000. CDC HIV/Hepatitis/STD/TB Prevention News Update. Centers for Disease Control and Prevention, Atlanta, GA.

Levin, S., Kruger, J., 2002. Substance abuse among older adults: a guide for social service providers. In: Treatment Improvement Protocol 26, Substance Abuse and Mental Health Services Administration. Center for Substance Abuse Treatment, Rockville, MD.

Levy, J.A., 1998. AIDS and injecting drug use in later life. Research on Aging 20, $776-798$.

Lewis, D.C., 1997. The role of the generalist in the care of the substance-abusing patient. The Medical Clinics of North America 81, 831-843.

Lieberman, R., 2000. HIV in older Americans: an epidemiologic perspective. Journal of Midwifery \& Women's Health 45, 176-182.

Lohse, N., Hansen, A.-B.E., Pedersen, G., Kronborg, G., Gerstoft, J., Sorensen, H.T., Vai'th, M., Obel, N., 2007. Survival of persons with and without HIV infection in Denmark, 1995-2005. Annals of Internal Medicine 45, 87-95.

Lubke, G.H., Muthen, B., 2005. Investigating population heterogeneity with factor mixture models. Psychological Methods 10, 21-39.
McFarland, W., Chen, S., Hsu, L., Schwarcz, S., Katz, M., 2003. Low socioeconomic status is associated with a higher rate of death in the era of highly active antiretroviral therapy, San Francisco. Journal of Acquired Immune Deficiency Syndromes (1999) 33, 96-103.

Monga, N., Rehm, J., Fischer, B., Brissette, S., Bruneau, J., El-Guebaly, N., Noel, L., Tyndall, M., Wild, C., Leri, F., Fallu, J.S., Bahl, S., 2007. Using latent class analysis (LCA) to analyze patterns of drug use in a population of illegal opioid users. Drug and Alcohol Dependence 88, 1-8.

Muthen, B., 1992. Latent variable modeling in epidemiology. Alcohol Health and Research World 16, 286-292.

Muthen, B., 2004. Growth mixture modeling and related techniques for longitudinal data. In: Kaplan, D. (Ed.), Handbook of Quantitative Techniques for Longitudinal Data. Sage Publishers, Newbury Park, CA, pp. 345-368.

Muthen, B., 2006. Should substance use disorders be considered as categorical or dimensional? Addiction (Abingdon, England) 101 (Suppl. 1), 6-16.

Muthen, B., 2008. Latent variable hybrids: overview of old and new models. In: Hancock, G.R., Samuelsen, K.M. (Eds.), Advances in Latent Variable Mixture Models. Information Age Publishing, Inc., Charlotte, NC, pp. 1-24.

Muthen, L.K., Muthen, B., 2007. Mplus User's Guide. Muthen \& Muthen, Los Angeles.

Office of Applied Studies, 2007. Naitonal survey of substance abuse treatment services (N-SSATS): 2006. Data on Substance Abuse Treatment Facilities. Substance Abuse and Mental Health Services Administration, Rockville, MD.

Orlando, M., Tucker, J.S., Ellickson, P.L., Klein, D.J., 2004. Developmental trajectories of cigarette smoking and their correlates from early adolescence to young adulthood. Journal of Consulting and Clinical Psychology 72, 400-410.

Orlando, M., Tucker, J.S., Ellickson, P.L., Klein, D.J., 2005. Concurrent use of alcohol and cigarettes from adolescence to young adulthood: an examination of developmental trajectories and outcomes. Substance Use \& Misuse 40, 1051-1069.

Osborne, G.B., Fogel, C., 2008. Understanding the motivations for recreational marijuana use among adult Canadians. Substance Use \& Misuse 43, 539-572, discussion 573-539, 585-537.

Palella Jr., F.J., Baker, R.K., Moorman, A.C., Chmiel, J.S., Wood, K.C., Brooks, J.T., Holmberg, S.D., 2006. Mortality in the highly active antiretroviral therapy era: changing causes of death and disease in the HIV outpatient study. Journal of Acquired Immune Deficiency Syndromes (1999) 43, 27-34.

Pitts, M., Grierson, J., Misson, S., 2005. Growing older with HIV: a study of health, social and economic circumstances for people living with HIV in Australia over the age of 50 years. AIDS Patient Care \& STDs 19, 460-465.

Rabkin, J.G., McElhiney, M.C., Ferrando, S.J., 2004. Mood and substance use disorders in older adults with HIV/AIDS: methodological issues and preliminary evidence. AIDS 18 (Suppl. 1), S43-S48.

Reid, M.C., Anderson, P.A., 1997. Geriatric substance use disorders. The Medical Clinics of North America 81, 999-1016.

Reid, M.C., Boutros, N.N., O'Connor, P.G., Cadariu, A., Concato, J., 2002. The healthrelated effects of alcohol use in older persons: a systematic review. Substance Abuse 23, 149-164.

Robins, L.N., Wing, J., Wittchen, H.U., Helzer, J.E., Babor, T.F., Burke, J., Farmer, A., Jablenski, A., Pickens, R., Regier, D.A., et al., 1988. The composite international diagnostic interview. An epidemiologic instrument suitable for use in conjunction with different diagnostic systems and in different cultures. Archives of General Psychiatry 45, 1069-1077.

Rosenberg, H., 1995. The elderly and the use of illicit drugs: sociological and epidemiological considerations. The International Journal of the Addictions 30, 1925-1951

Safren, S.A., O'Cleirigh, C., Tan, J.Y., Raminani, S.R., Reilly, L.C., Otto, M.W., Mayer, K.H., 2009. A randomized controlled trial of cognitive behavioral therapy for adherence and depression (CBT-AD) in HIV-infected individuals. Health Psychology $28,1-10$.

Schlaerth, K.R., 2007. Older adults and illegal drugs. Geriatrics Aging 10, 361-364.

Schlaerth, K.R., Splawn, R.G., Ong, J., Smith, S.D., 2004. Change in the pattern of illegal drug use in an inner city population over 50: an observational study. Journal of Addictive Diseases 23, 95-107.

Shapiro, M.F., Morton, S.C., McCaffrey, D.F., Senterfitt, J.W., Fleishman, J.A., Perlman, J.F., Athey, L.A., Keesey, J.W., Goldman, D.P., Berry, S.H., Bozzette, S.A., 1999. Variations in the care of HIV-infected adults in the United States: results from the HIV cost and services utilization study. Journal of American Medical Association $281,2305-2315$.

Sim, J., Wright, C.C., 2005. The Kappa Statistic in Reliability Studies: Use, Interpretation, and Sample Size Requirements. Physical Therapy 85, 257-268.

Simoni-Wastila, L., Yang, H.K., 2006. Psychoactive drug abuse in older adults. The American Journal of Geriatric Pharmacotherapy 4, 380-394.

Song, J.Y., Safaeian, M., Strathdee, S.A., Vlahov, D., Celentano, D.D., 2000. The prevalence of homelessness among injection drug users with and without HIV infection. Journal of Urban Health 77, 678-687.

Sterne, J.A., May, M., Costagliola, D., de Wolf, F., Phillips, A.N., Harris, R., Funk, M.J. Geskus, R.B., Gill, J., Dabis, F., Miro, J.M., Justice, A.C., Ledergerber, B., Fatkenheuer, G., Hogg, R.S., Monforte, A.D., Saag, M., Smith, C., Staszewski, S., Egger, M., Cole, S.R., 2009. Timing of initiation of antiretroviral therapy in AIDS-free HIV-1infected patients: a collaborative analysis of 18 HIV cohort studies. Lancet 373, 1352-1363.

Strathdee, S.A., Galai, N., Safaiean, M., Celentano, D.D., Vlahov, D., Johnson, L., Nelson, K.E., 2001. Sex differences in risk factors for HIV seroconversion among injection drug users: a 10-year perspective. Achieves of International Medicines 161, 1281-1288. 
Substance Abuse and Mental Health Services Administration, 2009. Results from the 2008 National Survey on Drug Use and Health: National Findings. NSDUH Series H-36. Office of Applied Studies, Rockville, MD.

Tardiff, K., Marzuk, P.M., Leon, A.C., Hirsch, C.S., Portera, L., Hartwell, N., 1997. HIV infection among victims of accidental fatal drug overdoses in New York City. Addiction (Abingdon, England) 92, 1017-1022.

Tucker, J.S., Ellickson, P.L., Orlando, M., Klein, D.J., 2006. Cigarette smoking from adolescence to young adulthood: women's developmental trajectories and associates outcomes. Womens Health Issues 16, 30-37.
Wang, C., Vlahov, D., Galai, N., Cole, S.R., Bareta, J., Pollini, R., Mehta, S.H., Nelson, K.E., Galea, S., 2005. The effect of HIV infection on overdose mortality. AIDS 19, 935-942.

Ware Jr., J., Kosinski, M., Keller, S.D., 1996. A 12-item short-form health survey: construction of scales and preliminary tests of reliability and validity. Medical Care 34, 220-233.

Zanjani, F., Saboe, K., Oslin, D., 2007. Age difference in rates of menta health/substance abuse and behavioral care in HIV-positive adults. AIDS Patient Care and STDs 21, 347-355. 